\title{
Competências da Cidadania Digital: especificação e avaliação de uma proposta de experiência de ensino-aprendizagem
}

\author{
Digital Citizenship Skills: specification and evaluation of a teaching-learning experience \\ proposal
}

\begin{abstract}
Gilvaneide Francisca Gomes ${ }^{1}$, Katyeudo Karlos Sousa Oliveira ${ }^{2}$, Ricardo André Cavalcante Souza ${ }^{1}$
${ }^{1}$ Universidade Federal Rural de Pernambuco, Pernambuco, Brasil.

${ }^{2}$ Universidade de São Paulo, São Paulo, Brasil.
\end{abstract}

\begin{tabular}{l}
\hline I N F O A R T I G O \\
\hline Palavras-chave: \\
Cidadania Digital, \\
Identidade Digital, \\
Educação 4.0, \\
Habilidades, \\
Transformação Digital.
\end{tabular}

\section{ARTICLE INFO}

\section{Keywords:}

Digital Citizenship,

Digital Identity,

Digital Transformation,

Education 4.0,

Skills.

\begin{abstract}
RES U M O
Cidadania digital é a capacidade de usar a tecnologia e as mídias sociais de maneira ética, segura e responsável. No entanto, pesquisas recentes mostram um baixo nível de maturidade da cidadania digital entre os jovens. Mas, a cidadania digital pode ser alcançada por meio de habilidades digitais que podem ser ensinadas e aprendidas. Assim, o objetivo deste trabalho é apresentar a especificação e avaliação de uma proposta de ensinoaprendizagem para estimular e exercitar habilidades digitais em alunos para o alcance da cidadania digital, por meio de habilitadores para a transformação digital rumo à Educação 4.0. A proposta foi apresentada e avaliada por 29 educadores. Os resultados indicam a capacidade de estimular as competências digitais dos alunos, auxiliando na formação de uma identidade digital ética, segura e responsável, exercendo a comunicação empática nas redes sociais e contribuindo para a criação de uma boa reputação digital.
\end{abstract}

\begin{abstract}
A B S T R A C T
Digital citizenship is the ability to use technology and social media in an ethical, safe and responsible way. However, recent surveys show a low level of maturity of digital citizenship among young people. But digital citizenship can be achieved through digital skills that can be taught and learned. Thus, the objective of this work is to present the specification and evaluation of a teaching-learning proposal to stimulate and exercise digital skills in students to achieve digital citizenship, through drivers for the digital transformation towards Education 4.0. The proposal was presented and evaluated by 29 educators. The results indicate the ability to stimulate the digital skills of students, helping to form an ethical, safe and responsible digital identity, exercising empathic communication on social networks and contributing to the creation of a good digital reputation.
\end{abstract}




\author{
Correspondência para autores: \\ gilvaneidegomes27@gmail.com (Gomes, G.F.) (ORCID: 0000-0002-2524-5691), \\ karlos oliveira@usp.br (Oliveira, K.K.S.) (ORCID: 0000-0002-4414-1599), \\ ricardo.souza@ufrpe.br (Souza, R.A.C.) (ORCID: 0000-0002-2639-3143).
}

\title{
1. Introdução
}

A educação desempenha um papel fundamental no desenvolvimento de competências que possibilitam com que as pessoas possam contribuir e se beneficiar de um futuro inclusivo e sustentável (OLIVEIRA et al., 2020; OLIVEIRA; SOUZA, 2021). Aprender a formar objetivos claros, trabalhar com pessoas com perspectivas diferentes, encontrar oportunidades inexploradas e identificar soluções para grandes problemas será essencial para o futuro (WEF, 2020). A educação precisa capacitar os estudantes com as competências que eles necessitam para se tornarem cidadãos engajados e responsáveis (OECD, 2018).

Para o relatório Education 2030 learning framework (OECD, 2018), o desenvolvimento de uma competência envolve a mobilização de conhecimentos, habilidades, atitudes e valores para atender demandas complexas. O conhecimento envolve o saber a aprender e fazer, para aplicar o conhecimento existente por meio de um conjunto lógico de ações para gerar novo conhecimento ou resolver um problema. As habilidades referem-se as capacidades cognitivas e metacognitivas (pensamento crítico, criatividade, etc.), sociais e emocionais (empatia, colaboração, etc.) e práticas (fluência digital, programação, etc.). As atitudes e valores, para a mediação do uso de conhecimentos e habilidades, são adquiridos ao longo da vida como, motivação, respeito à diversidade e à vida.

De acordo com Park (2019), a capacidade de desenvolver competências é algo a ser aprendido usando um processo sequencial de reflexão, antecipação e ação. A prática reflexiva é a capacidade de assumir uma posição crítica ao decidir, escolher e agir, voltar atrás do que é conhecido ou assumido e olhar para uma situação de outras perspectivas. Antecipação mobiliza habilidades cognitivas, como pensamento analítico ou crítico, para prever o que pode ser necessário no futuro ou como as ações tomadas hoje podem ter consequências para o futuro. A reflexão e a antecipação são precursores de ações responsáveis.

Os estudantes precisam ser preparados com as competências digitais exigidas para a Educação 4.0 (WEF, 2020). Segundo Park (2019), as competências digitais estão diretamente associadas aos níveis de maturidade digital: (1) cidadania digital; (2) criatividade digital; e (3) competitividade digital. O nível de maturidade digital básico é a cidadania digital, definida como a capacidade de usar tecnologia e mídia digital de modo seguro, ético e responsável. A cidadania digital está associada à cultura digital em currículos e modelos de referências no Brasil (CIEB, 2018; BRASIL, 2018). Pesquisas recentes mostram dados alarmantes relacionados à cidadania digital: aproximadamente $60 \%$ das crianças de 8 a 12 anos de idade a nível global, estão vulneráveis ao risco cibernético, incluindo o cyberbullying (COSI, 2020); 31\% dos jovens entre 9 e 17 anos no Brasil relatam não saber "verificar se uma informação encontrada na Internet está correta"; enquanto $44 \%$ relatam que tiveram algum tipo contato online com desconhecidos (CGI.BR, 2018).

As competências digitais permitem que as pessoas saibam, além de usar um computador ou smartphone, enfrentar os desafios da atualidade, como vícios online, roubo de identidade, privacidade online e propagação de informações digitais (WEF, 2018). As competências digitais necessárias para o alcance da cidadania digital tornam-se ainda mais relevantes em um cenário de convívio ou pós-pandemia do COVID19, no qual as relações educacionais, sociais e de trabalho serão cada vez mais mediadas por tecnologias 
digitais (WHITING, 2020).

Também é importante ressaltar outro problema: a educação ainda é orientada por modelos introduzidos há décadas, ao mesmo tempo que a sociedade entra na Quarta Revolução Industrial (WEF, 2016). As novas condições de crescimento econômico e social causaram o surgimento de mudanças nas habilidades necessárias para que as pessoas tenham a capacidade de contribuir com a economia e como ela trabalham, dando maior ênfase às questões sobre a adequação dos sistemas educacionais atuais, a chamada Educação 4.0 (WEF, 2020). Considerando o contexto discutido, De Sousa Oliveira e Souza (2020) apresentam habilitadores da Educação 4.0. Tais habilitadores guiam o desenho de estratégias para reorganizar o processo de ensinoaprendizagem para um público de nativos digitais, considerando os conceitos de: (i) fazer digital, com conhecimentos e competências técnicas; e (ii) ser digital, incorporando habilidades, mentalidade e atitudes digitais.

Neste sentido, o objetivo deste trabalho é analisar a especificação e a avaliação de uma proposta de experiência de ensino-aprendizagem, fundamentada por habilitadores para da Educação 4.0 mapeados por De Sousa Oliveira e Souza (2020), visando exercitar e estimular nos estudantes competências de um cidadão digital, através de atividades em sala de aula e extraclasse.

Além desta seção introdutória, este trabalho está organizado em mais quatro seções. A Seção 2 descreve o arcabouço teórico e as etapas do método de pesquisa para o desenvolvimento do trabalho. $\mathrm{Na}$ Seção 3 e na Seção 4 são detalhadas as etapas do método de pesquisa e os resultados obtidos, respectivamente. Na Seção 5 é realizada uma breve análise dos resultados. Finalmente, na Seção 6, é descrita a conclusão.

\section{Arcabouço teórico e método de pesquisa}

A Educação 4.0 deve abordar a mudança no conteúdo de aprendizagem, assim, ajudando os estudantes a criar relacionamentos saudáveis com a tecnologia, assimilar os princípios de gerenciamento de riscos e segurança digital e conscientizar-se sobre os deveres de desenvolvedores e consumidores responsáveis da tecnologia (WEF, 2020).
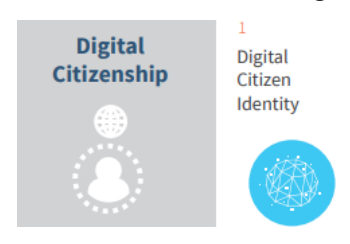

Figura $1-$

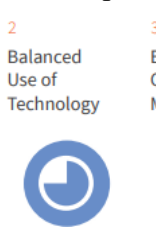

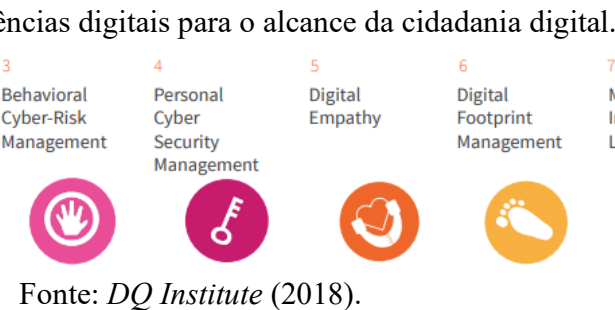

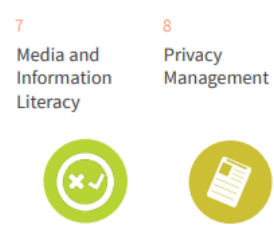

O nível de maturidade digital inicial para habilitar uma transformação digital em direção à Educação 4.0 é a cidadania digital (WEF, 2018). De acordo com Park (2019), as competências digitais para o alcance da cidadania digital são: identidade do cidadão digital - manter uma identidade saudável como um cidadão digital; uso equilibrado de tecnologia - gerenciar a vida online e offline de modo equilibrado; gestão comportamental de risco cibernético - identificar, mitigar e gerenciar riscos relacionados ao comportamento online (cyberbullying, assédio, etc.); gestão da proteção pessoal online - detectar ameaças cibernéticas (invasão, fraude, etc.) e usar estratégias de segurança e ferramentas de proteção; empatia digital - apoiar outras pessoas que expressam sentimentos e preocupações online; gestão do rastro digital - compreender as consequências dos atos no mundo virtual e construir uma reputação digital positiva; letramento da informação e mídia - encontrar e analisar informação e mídia digitais com senso crítico; gestão da privacidade - manipular 
com discrição as informações pessoais compartilhadas online.

Figura 2 - Habilitadores para Transformação Digital em direção à Educação 4.0.

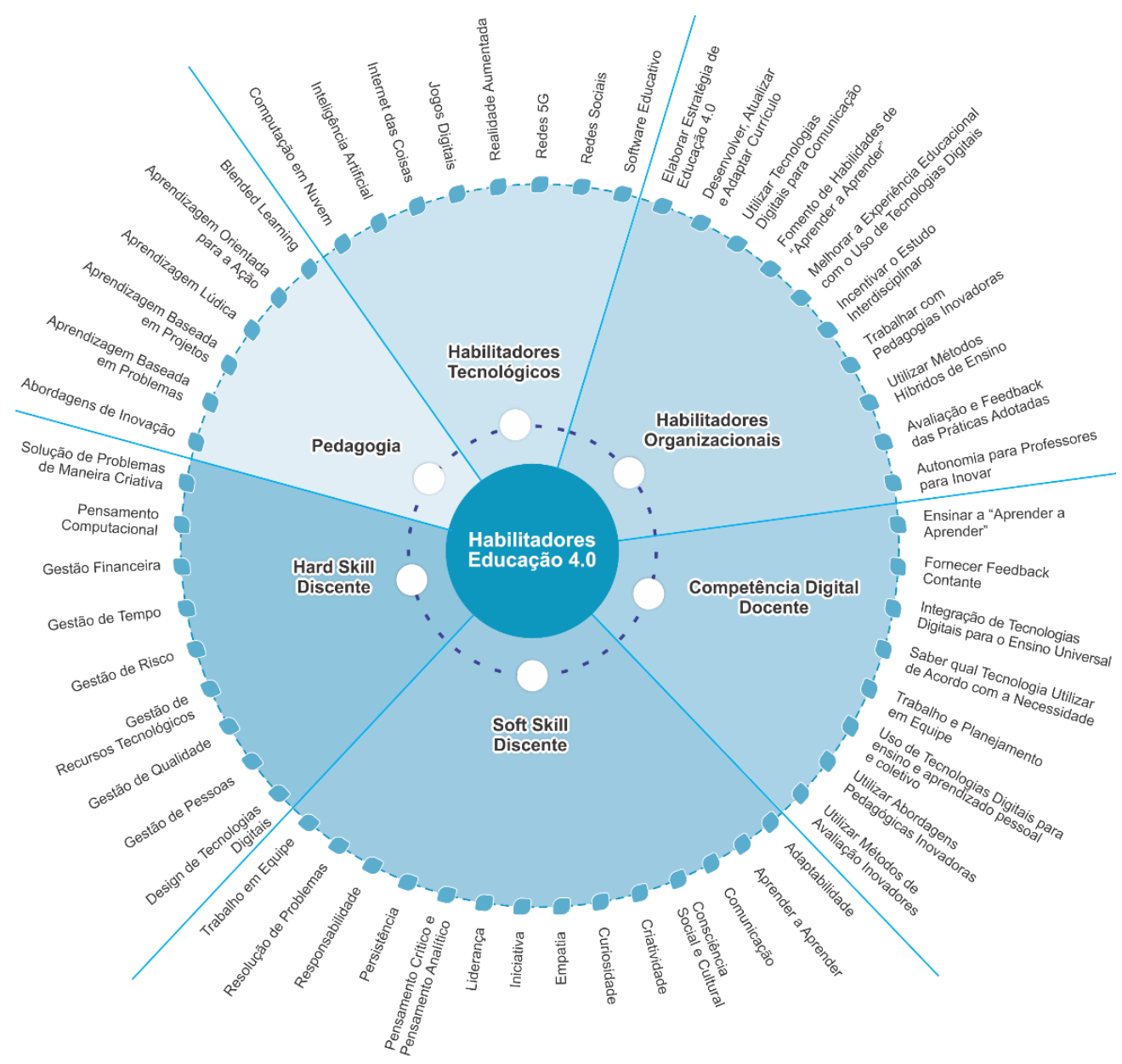

Fonte: De Sousa Oliveira e Souza (2020).

A educação é o principal meio para equipar as pessoas com as competências da cidadania digital (PARK, 2019). Mas, para tanto, é necessário repensar as abordagens educacionais. De Sousa Oliveira e Souza (2020) relatam que as abordagens educacionais precisam tratar de maneira integrada/holística as dimensões que agrupam os habilitadores da Transformação Digital em direção à Educação 4.0 (Figura 2): uso de tecnologias digitais, considerando a individualidade dos estudantes; adoção de processos e práticas organizacionais em conformidade com as novas relações sociais e de trabalho; equipar professores com competências digitais (fazer e ser) para lidar com estudantes considerados nativos digitais; equipar estudantes com as habilidades técnicas, cognitivas, sociais e emocionais necessárias para o aprendizado e trabalho do século XXI; e adoção de pedagogias inovadoras com foco no ensino e aprendizagem com a finalidade de resolver um problema ou realizar uma tarefa.

Tais habilitadores foram agrupados por categoria, encontrados a partir da análise de relatórios produzidos por organizações internacionais que mantêm fóruns permanentes de discussão sobre educação e economia em âmbito mundial: OECD - Organisation for Economic Co-operation and Development, P21 Partnership for $21^{\text {st }}$ Century Learning, The United Kingdom Open University e WEF - World Economic Forum. 
Entre os principais habilitadores tecnológicos da transformação digital na educação estão os softwares educacionais. A combinação entre hard skills e soft skills é essencial para alcançar liderança e sucesso profissional. A transformação digital na educação deve considerar a formação dos professores e a organização das instituições de ensino (DE SOUSA OLIVEIRA; SOUZA, 2020). Segundo Goh e AbdulWahab (2020), os professores representam a linha de frente na formação dos estudantes, e necessitam estar capacitados para usar as novas metodologias de ensino em um mundo digitalizado.

De acordo com De Sousa Oliveira e Souza (2020), no contexto da educação, a transformação digital envolve repensar os processos de ensino e aprendizado para um público de nativos digitais, considerando os aspectos práticos da transformação digital, por meio de conhecimentos e competências técnicas, e ser digital, por meio da incorporação de habilidades, mentalidade e atitudes digitais.

Visando atingir o objetivo deste trabalho, é realizada a especificação e avaliação de uso dos habilitadores supracitados em uma proposta de experiência de ensino-aprendizagem. Esta proposta, visa estimular e exercitar algumas das competências da cidadania digital. A Figura 3 mostra, em Business Process Model and Notation (BPMN), o fluxo dos passos realizados para desenvolvimento do trabalho. Foi utilizado este método para que fosse possível elaborar a proposta através de um levantamento e estabelecimento de um conjunto de informações sobre a temática, para que fosse possível disponibilizar mais informações para os professores e aumentar a familiaridade deles com a proposta. Ainda, todas as etapas foram estabelecidas de forma remota, devido à quarentena do COVID-19.

O fluxo (pool) "Proposta e avaliação de estratégia para cidadania digital" é disposto em duas raias (swimlanes) com o intuito de separar as atividades de responsabilidades dos atores envolvidos: os autores do trabalho e os educadores responsáveis pela avaliação da abordagem proposta. O trabalho iniciou com a especificação de uma proposta de experiência de ensino-aprendizagem, onde foi procurado desenhar/projetar atividades para estimular e exercitar competências digitais tidas como necessárias para a cidadania digital, a partir do uso de habilitadores da Educação 4.0.

Figura 3 - Fluxo do método de pesquisa.

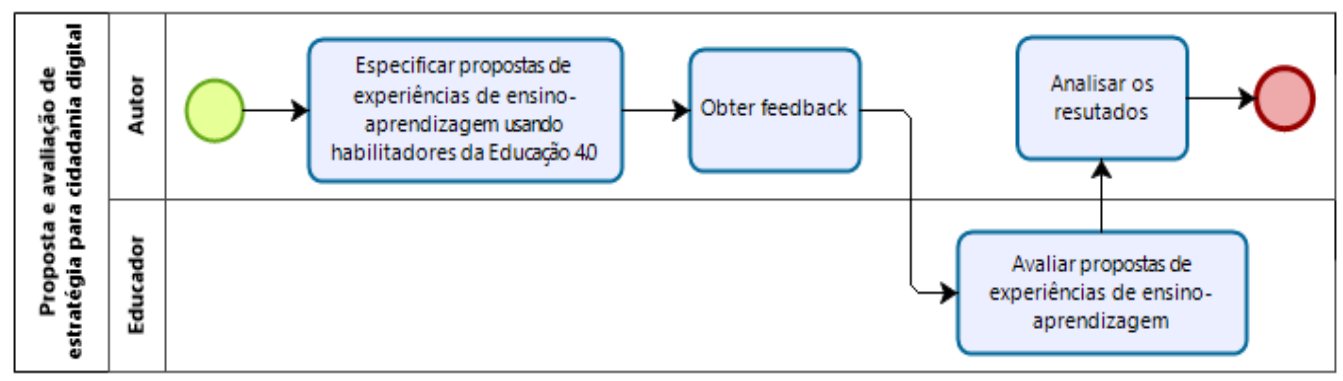

Fonte: Elaborado pelos Autores (2021).

Em seguida, foi realizada a atividade 'Obter feedback' que consistiu na preparação de uma apresentação, na forma de vídeo, e na elaboração e aplicação de um questionário eletrônico para avaliação da proposta. Um grupo de 29 educadores foram contatados utilizando-se de diferentes canais de comunicação, por exemplo, redes sociais e e-mail. Assim, cada educador assistiu ao vídeo e respondeu o questionário eletrônico de avaliação da proposta. Por fim, os resultados das avaliações foram analisados e discutidos. Nas próximas seções, os passos do método de pesquisa são descritos em mais detalhes. 


\section{Especificar proposta usando habilitadores da Educação 4.0}

A proposta de experiência de ensino-aprendizagem procura introduzir atividades no ambiente escolar e fora dele para estimular e exercitar nos estudantes as seguintes competências para a cidadania digital: Identidade do cidadão digital - analisar o perfil digital dos estudantes; Gestão comportamental de risco cibernético - discutir o risco de propagação de notícias falsas (fake news); Empatia digital - debater ideias, contribuindo e respeitando opiniões alheias; e Gestão do rastro digital - debater os riscos de exposição verbal e visual na Internet.

A dinâmica básica da proposta de experiência de ensino-aprendizagem consiste de: (i) em sala de aula, o professor acessa os perfis dos estudantes em uma rede social (ex: Facebook) e analisa as postagens; (ii) o professor busca debater e conscientizar os estudantes acerca dos riscos da exposição na Internet, como perfis e notícias falsas; (iii) o professor debate com os estudantes estratégias para verificar a veracidade de notícias e informações encontradas na rede; (iv) o professor cria um grupo, por meio de aplicativos de mensagens instantâneas como WhatsApp ou Telegram, para expor um determinado assunto atual que desperte o interesse e discussão entre os estudantes, onde eles serão encorajados a expor suas perspectivas através de opiniões e justificar a concordância ou não em relação a opinião de outros estudantes; (v) o professor media o debate para garantir discussões éticas, propositivas e responsáveis; (vi) por fim, o professor expõe as considerações dele sobre a experiência realizada e incentiva os estudantes a relatarem as lições aprendidas.

Através desta experiência, os estudantes terão a oportunidade de adquirir conhecimento sobre a construção da sua identidade e reputação digital, compreenderão como tais mídias podem influenciar na forma de gerenciar e obter informações e poderão aprender como gerenciar com responsabilidade às informações expostas nas mídias digitais, com o intuito de trazer consequências positivas para as suas vidas pessoal e acadêmica. A proposta de experiência de ensino-aprendizagem, para ser bem planejada e executada, necessita usar habilitadores da Educação 4.0 (DE SOUSA OLIVEIRA; SOUZA, 2020). Dessa forma, o Quadro 1 apresenta a descrição de como cada habilitador instanciado é utilizado nesta proposta de modo a viabilizar os resultados esperados.

Quadro 1 - Habilitadores da proposta de experiência de ensino-aprendizagem.

\begin{tabular}{|c|l|}
\hline Habilitador & \multicolumn{1}{c|}{ Descrição } \\
\hline $\begin{array}{c}\text { Habilitadores } \\
\text { Tecnológicos }\end{array}$ & $\begin{array}{l}\text { Redes Sociais: a rede social Facebook (e WhatsApp ou Telegram), permite a interação social através } \\
\text { do compartilhamento e criação de conteúdos colaborativos. O uso adequado desta mídia permite que } \\
\text { o usuário desenvolva senso crítico e realize postagens, interações e compartilhamento de informações } \\
\text { de forma responsável e ética. }\end{array}$ \\
\hline $\begin{array}{c}\text { Fomento (aperfeiçoamento) de Habilidades de "Aprender a Aprender": estimular o } \\
\text { Hesenvolvimento das competências necessárias para o aluno ser um cidadão digital crítico, através da } \\
\text { Organizacionais }\end{array}$ & $\begin{array}{l}\text { Melhorar a Experiência Educacional com o Uso de Tecnologias Digitais: estimular o uso das } \\
\text { tecnologias existentes no ambiente escolar de forma que os professores possam realizar aulas práticas } \\
\text { e diferenciadas. } \\
\text { Utilizar métodos híbridos de ensino: proporcionar ao aluno e ao professor a experiência de realizar } \\
\text { as atividades independente de espaço físico e tempo, fazendo a mesclagem do ensino online ao ensino } \\
\text { tradicional, mediado pelas tecnologias digitais. }\end{array}$ \\
\hline
\end{tabular}




\begin{tabular}{|c|c|}
\hline $\begin{array}{c}\text { Competência } \\
\text { Digital Docente }\end{array}$ & $\begin{array}{l}\text { Ensinar a "aprender a aprender": o professor usará o seu conhecimento teórico atrelado a prática } \\
\text { para mediar o ensino, onde ele desenvolverá métodos inovadores de ensino que contribuam para a } \\
\text { realização das atividades através das mídias sociais e da tecnologia. } \\
\text { Fornecer feedback constante: o professor estimulará o aluno através de debates/discussões a expor } \\
\text { seus pontos de vistas, bem como na atividade utilizando as redes sociais, analisando com } \\
\text { responsabilidade e cautela o que foi explicitado pelos os alunos pontuando de forma ética as questões } \\
\text { e buscando manter o aluno ativo na prática da atividade. } \\
\text { Uso de tecnologias digitais para ensino e aprendizado pessoal e coletivo: utilizar a tecnologia para } \\
\text { pesquisar as informações e estruturar o plano de aula, com o intuito de produzir conteúdo de qualidade } \\
\text { para auxiliar nas aulas práticas e usar estas tecnologias com eficácia na mediação do ensino. } \\
\text { Utilizar métodos de avaliação inovadores: avaliar os alunos de acordo com os seus conhecimentos } \\
\text { ao realizar às atividades práticas, desempenho ao utilizar os recursos tecnológicos, participação nos } \\
\text { debates e entrega dos resultados. }\end{array}$ \\
\hline Soft Skill Discente & $\begin{array}{l}\text { Aprender a aprender: o aluno poderá aprender a se posicionar no meio digital e a formar sua } \\
\text { identidade digital à medida que ele terá acesso aos conteúdos expostos pelos professores e participado } \\
\text { dos debates em sala de aula, bem como pondo em prática o que aprendeu. } \\
\text { Comunicação: possibilitará ao aluno expor suas ideias de forma clara, com dialeto próprio da internet } \\
\text { (“internetês"), onde eles saberão respeitar as informações que divergentes, preservando a sua } \\
\text { reputação na rede. } \\
\text { Consciência social e cultural: o aluno terá ciência ao desenvolver as atividades no meio digital que } \\
\text { irá se relacionar com diferentes indivíduos, grupos e comunidades onde estes devem ser respeitados } \\
\text { para que esta interação ocorra de forma harmônica e ética. } \\
\text { Pensamento crítico e Pensamento Analítico: o senso crítico do aluno será aguçado possibilitando a } \\
\text { ele analisar e questionar na rede a postura dos outros e de si mesmo. Ao debater sobre os riscos de } \\
\text { exposição ou compartilhamento de informações na rede, ele poderá se tornar um indivíduo mais } \\
\text { consciente sobre sua comunicação no mundo digital e dos demais usuários. }\end{array}$ \\
\hline & $\begin{array}{l}\text { Gestão de risco: Gerenciar as redes sociais evitando se expor em demasia e analisar os conteúdos } \\
\text { antes de postar para evitar o compartilhamento de notícias falsas, as denominadas fake news. } \\
\text { Gestão de qualidade: utilizar o senso crítico para analisar a qualidade das postagens que circulam na } \\
\text { rede, bem como, a que irá postar e compartilhar, como também outros conteúdos e troca de } \\
\text { informações na rede. }\end{array}$ \\
\hline Pedagogia & $\begin{array}{l}\text { Aprendizagem orientada para a ação: a teoria atrelada à prática, a partir do momento que o } \\
\text { professor explana um assunto e busca soluções juntamente com a turma, ocasiona a aprendizagem do } \\
\text { aluno através das ações e das reflexões sobre essas ações, levando o aluno a pensar melhor sobre } \\
\text { atitudes futuras e ter maior segurança ao postar e compartilhar informações na rede como também } \\
\text { melhorar sua interação social. }\end{array}$ \\
\hline
\end{tabular}

Fonte: Elaborado pelos Autores (2021).

\section{Procedimentos Metodológicos}

Esta atividade foi iniciada a partir da elaboração de uma apresentação em vídeo ${ }^{1}$ da proposta de experiência de ensino-aprendizagem retratada; também, de um questionário eletrônico com o intuito de avaliar

\footnotetext{
1 https://youtu.be/upkJ2dgr4ec
} 
a proposta. Após, o vídeo e o questionário foram apresentados para educadores (professores e pesquisadores educacionais), contatados através de redes sociais e e-mail.

\subsection{Avaliando propostas de experiências de ensino-aprendizagem}

Esta atividade, compreende a visualização e avaliação da proposta de experiência de ensinoaprendizagem por 29 educadores. Assim, a Figura 4(a) exibe o quantitativo do perfil dos avaliadores, onde: "Professor de Ensino Superior" (13) e "Professor de Ensino Médio" (8), foram os respondentes com maior destaque. Na Figura 4(b) é evidenciado o nível de formação dos avaliadores, em que: "Especialização" (15) e "Mestrado" (10) foram os mais apontados.

Figura 4 - (a) Perfil e (b) Nível de formação dos avaliadores.

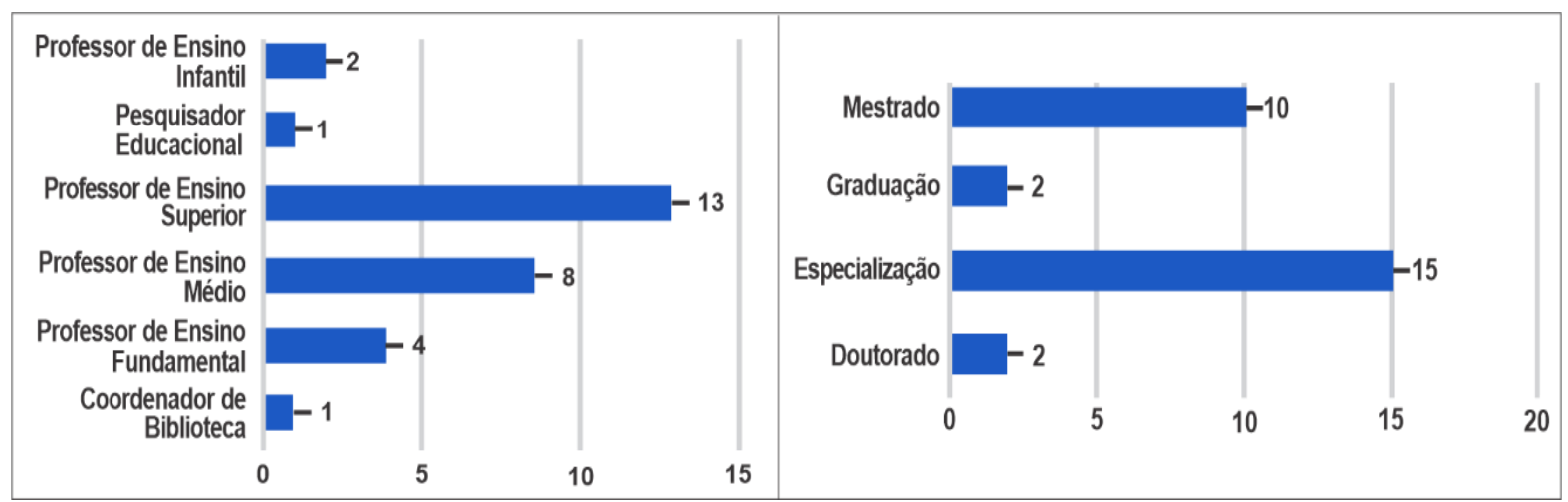

Fonte: Elaborado pelos Autores (2021).

Na sequência, foi perguntado qual a área de atuação dos educadores, assim, possibilitando detalhar melhor o perfil deles. A Figura 5 mostra o quantitativo, com maior destaque para atuações em "Língua Portuguesa" (6) e "Tecnologia" (7).

Figura 5 - Áreas de atuação dos avaliadores.

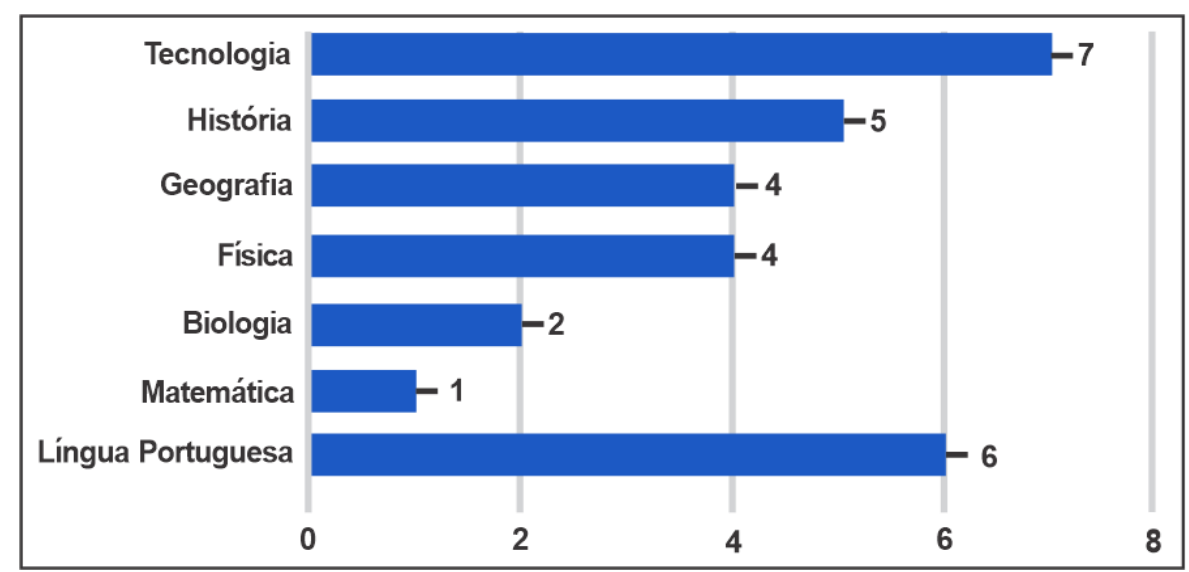

Fonte: Elaborado pelos Autores (2021).

\subsection{Analisando os resultados}

Esta atividade constitui-se da análise e discussão do resultado da avaliação da proposta de experiência pelos educadores. Inicialmente, foram analisadas as respostas sobre as seguintes questões: (Q1) "A experiência de ensino-aprendizagem proposta contribui para o estudante formar uma identidade digital 
(online) ética, segura e responsável?”; (Q2) “A experiência de ensino-aprendizagem proposta contribui para o estudante exercitar a comunicação empática nas redes sociais?"; e (Q3) "A experiência de ensinoaprendizagem proposta contribui para o estudante criar uma boa reputação digital?". Estas questões visam mostrar a percepção dos avaliadores sobre a integração de valores aos estudantes, considerando a escala Likert de 1 - "discordo totalmente" a 5 - "concordo totalmente". A Figura 6 sintetiza a avaliação sobre as questões Q1, Q2 e Q3.

Figura 6 - Avaliação da agregação de valor educacional aos estudantes.

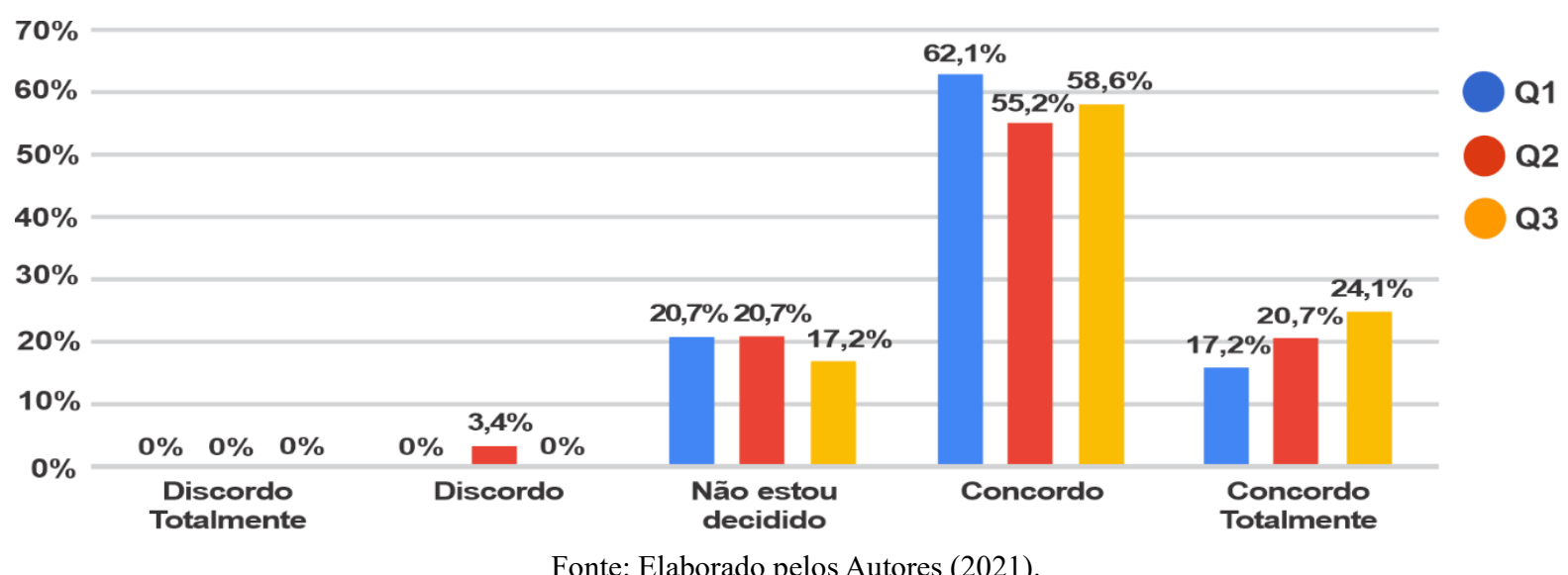

Segundo Park (2019), a competência digital "Identidade do cidadão digital" consiste em criar e gerenciar uma identidade digital saudável como cidadão digital integro. Assim, na análise de questão Q1, o resultado obtido mostra que $79,3 \%$ dos educadores concordam que a proposta de experiência contribui para que os estudantes possam formar uma identidade digital (online) ética, segura e responsável.

Já a competência digital "Empatia digital" consiste na capacidade de mostrar empatia em relação às necessidades e sentimentos próprios e dos outros em ações que aconteçam online. Desse modo, no resultado da questão Q2, observa-se que 75,9\% dos educadores concordam que a experiência de ensino-aprendizagem proposta, contribui para que os estudantes possam exercitar a comunicação empática nas redes sociais. Segundo (DQ INSTITUTE, 2018), a falta desta empatia, pode aumentar a ansiedade e pressões sociais, assim, acarretando em tempo excessivo online, algum tipo de dependência digital, cyberbullying, falta de privacidade online e disseminação de fake news.

Por fim, a competência digital "Gestão do rastro digital" versa sobre a reputação digital e suas consequências na vida real, e como gerenciá-la com responsabilidade. Assim, o resultado da questão Q3 mostra que $82,7 \%$ dos educadores concordam que a proposta de experiência contribui para o estudante criar uma boa reputação digital. Segundo Buchanan et al. (2017), ao invés de somente ensinar sobre segurança online e reduzir as "pegadas" (rastros) digitais, também é possível incentivar os estudantes a deixar "pegadas" digitais positivas, podendo ser um trunfo para eles no futuro.

A partir do feedback obtido, foi também possível analisar quais habilidades (skills), consideradas necessárias para o aprendizado e trabalho do século XXI, podem ser estimuladas pela proposta de experiência de ensino-aprendizagem. Para tanto, foram analisadas as respostas dos educadores sobre a seguinte questão: A proposta de experiência de ensino-aprendizagem contribui em equipar os estudantes com quais outras habilidades? A Figura 7 apresenta o resultado, considerando que os avaliadores poderiam escolher mais de uma alternativa. 
Figura 7 - Avaliação da agregação de habilidades do século XXI aos estudantes.

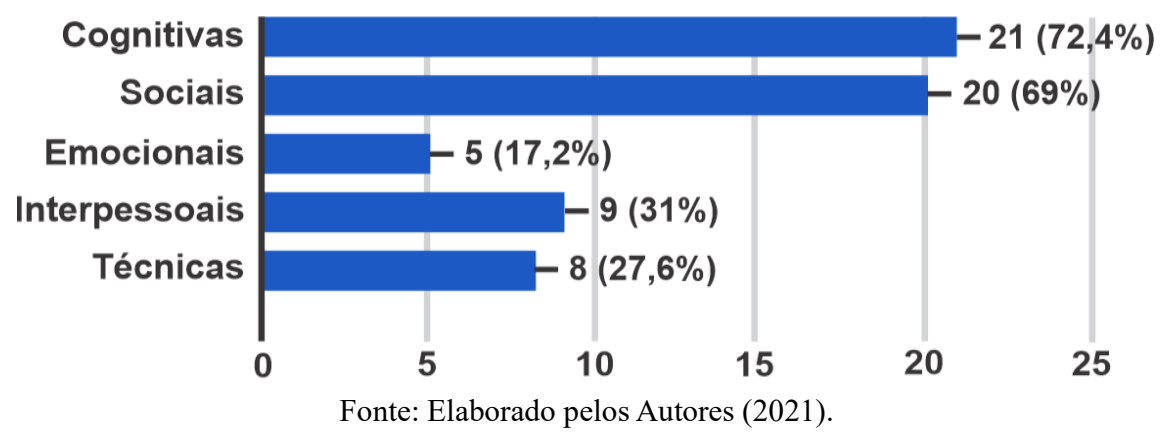

A Educação 4.0 tem por objetivo equipar estudantes com as habilidades técnicas, cognitivas, sociais e emocionais necessárias para o aprendizado do século XXI (WEF, 2020). Para (OECD, 2018), os estudantes necessitarão de habilidades cognitivas, sociais, emocionais, práticas e físicas, para empregarem seus conhecimentos em cenários desconhecidos e em constante evolução. O resultado da avaliação (Figura 7) mostra que a proposta de experiência de ensino-aprendizagem contribui em equipar os estudantes com habilidades do século XXI, com destaque para as habilidades cognitivas e sociais.

Por fim, foram analisadas as respostas sobre quais os benefícios que a proposta de experiência de ensino-aprendizagem poderia trazer para os professores. A Figura 8 apresenta o resultado, ressaltando que os avaliadores poderiam escolher mais de uma alternativa.

Figura 8 - Avaliação dos benefícios para os professores.

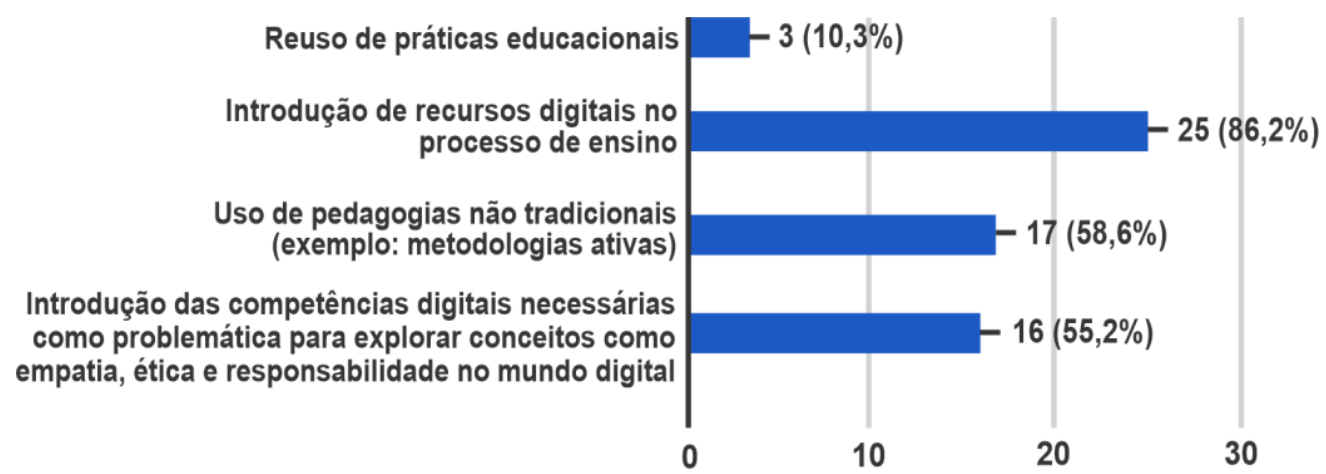

Fonte: Elaborado pelos Autores (2021).

Segundo Schleicher (2016), os professores devem inserir a tecnologia digital na prática do ensino e perceber avanço constante dos campos de conhecimento. Para De Sousa Oliveira e Souza (2020), os professores precisam ser equipados com competências digitais, envolvendo tecnologias, pedagogias inovadoras e a adoção de mentalidade e atitudes digitais. De acordo com (DQ INSTITUTE, 2018), em se tratando de competências digitais, faz necessário que o indivíduo seja dotado de Inteligência Digital, permitindo, assim, os indivíduos enfrentarem os desafios da vida digital e se adaptarem às suas demandas. $\mathrm{O}$ resultado da avaliação (Figura 8), mostra que a proposta de experiência de ensino-aprendizagem traz benefícios também para os professores, com destaque para "introdução de recursos digitais no processo de ensino" e "uso de pedagogias não tradicionais".

\section{Discussões}

Esta avaliação possibilitou um entendimento de que as novas abordagens pedagógicas são essenciais para fazer a educação atrativa para os estudantes. As habilidades sociais (soft skills) e técnicas (hard skills) 
devem ser alteradas de acordo a sociedade do século XXI, sendo importante que sejam orientadas de modo envolvente para que possam ser moldadas pelos estudantes.

Chen et al. (2021), realizaram uma revisão integrativa para investigar as diversas conceituações de Cidadania Digital, na literatura. Uma pesquisa sistemática identificou um total de 350 itens exclusivos que contêm "cidadania digital" no título ou nas palavras-chave publicadas até dezembro de 2018, com a maioria publicada após 2010. De acordo com os autores, há uma grande ausência de pesquisas empíricas com crianças e uma ausência de instrumentos de pesquisa relacionadas as competências digitais, como a cidadania digital.

Existem esforços para desenvolver programas de educação que incluam as competências digitais. Fediy, Protsai e Gibalova apresentam uma formação da cidadania digital de alunos do ensino fundamental, especificando os conceitos de cidadania digital dos alunos do ensino básico e cidadão digital.

Joshi, Neupane e Joshi (2021) desenvolveram um framework de competência digital, baseando-se no framework do DQ Institute, para professores de matemática desde a escola até a universidade. O framework sugere que os professores devem ter vinte e sete sub-habilidades em seis habilidades principais. Além disso, sugeriu que os professores devem ser sensíveis e cuidadosos com as políticas e os valores éticos no uso de tecnologias digitais nas atividades profissionais.

Quanto à Educação 4.0, Oliveira et al. (2021a) apresentaram a especificação e avaliação de propostas de uso de habilitadores da Educação 4.0, para a transferência e aquisição de conhecimentos de disciplinas básicas com a temática das causas e efeitos das mudanças climáticas. Os autores, discutiram os resultados da análise realizada com 53 educadores, apontando que as propostas possuíam potencial de agregar valor a estudantes e professores.

Oliveira et al. (2021b) discutem que a Educação 4.0 impulsiona a educação e desenvolve habilidades relevantes e tecnologias digitais. Mas para isto, os autores argumetam que os professores devem ser capacitados para o uso de tais tecnologias digitais no ensino. Utilizando-se deste argumento, Oliveira et al. (2021b) realizaram um estudo de caso com professores sobre uma ferramenta de software de suporte à Educação 4.0, uma ferramenta $W e b$, com algumas características, dentre elas um painel interativo com os habilitadores da transformação digital na educação. Os autores encontraram que a percepção de inovação dos professores foi positiva, principalmente, como um software habilitador da resolução criativa de problemas e da transformação do conhecimento, e ainda, concordaram com os indicadores de facilidade de uso e de utilidade de uso percebidos sobre a ferramenta.

Para Oliveira e Souza (2021), para abordar adequadamente os principais problemas da atualidade, é essencial existir um processo de transformação digital na educação. Assim sendo, os resultados obtidos neste estudo sugerem que os habilitadores para transformação digital em direção à Educação 4.0 têm a capacidade de auxiliar a no fomento às necessidades educacionais exigidas pela Quarta Revolução Industrial, principalmente no que diz respeito à introdução de recursos digitais no processo de ensino e às soft e hard skills imprescindíveis para o aprendizado dos estudantes.

Percebe-se que os estudantes também devem ser capacitados para usar tecnologia e mídia digital de maneira segura, responsável e ética. Ainda, as competências digitais, vistas como necessárias para a cidadania digital são cada vez mais relevantes, principalmente quando visuzaliza-se um cenário pandêmico em que as relações sociais são mediadas por tecnologias.

Na prática sugerida neste estudo, um dos diferenciais e contribuições foi a busca por reunir as principais contribuições referentes às competências digitais e Educação 4.0 em uma única abordagem. Outro 
fator, é a possibilidade de educar e capacitar os estudantes com as competências da cidadania digital, simultaneamente, é usado de forma holística as tecnologias digitais. Ainda, a experiência utiliza de pedagogias inovadoras para habilitar os professores com competências digitais e capacitar os estudantes com habilidades técnicas, interpessoais, sociais e cognitivas, as habilidades do século XXI.

\section{Conclusões}

A cidadania digital consiste do nível mais básico de maturidade digital e, portanto, pode ser considerado o ponto de partida para uma jornada de transformação da educação. Por outro lado, a educação é o meio mais eficiente para equipar os estudantes com as competências da cidadania digital. Nesse sentido, este trabalho apresentou a especificação e avaliação de uma proposta de experiência de ensino-aprendizagem a partir de instâncias de habilitadores da Educação 4.0 mapeados por De Sousa Oliveira e Souza (2020). A proposta objetivou estimular e exercitar nos estudantes as seguintes competências necessárias para o alcance da cidadania digital: identidade de cidadão digital íntegra; comportamento online empático, respeitoso e ético; proteção da privacidade digital; e boa reputação digital.

O diferencial da proposta de experiência de ensino-aprendizagem consiste no uso de tecnologias digitais, perspectivas organizacionais, aplicação de pedagogias não tradicionais, competências digitais do docente, e habilidades técnicas, interpessoais, sociais e cognitivas do discente, como estratégia em direção à Educação 4.0, que pode ser bastante útil em um cenário de convivência ou pós-pandemia do COVID-19. Em termos práticos, a abordagem proposta contribui em educar e conscientizar sobre habilidades, conhecimentos, atitude e valores que os estudantes devem aplicar no mundo virtual para se tornarem cidadãos digitais.

O feedback dos 29 educadores avaliadores indica concordância deles no que diz respeito ao estímulo às competências digitais pela abordagem proposta: auxilia na formação de uma identidade digital ética, segura e responsável; exercita a comunicação empática nas redes sociais; e contribui para criação de uma boa reputação digital. Além disso, os avaliadores apontam que a proposta de experiência de ensino-aprendizagem contribui em prover habilidades cognitivas e sociais nos estudantes; e inclusão de tecnologias digitais no processo de ensino, assim como o uso de pedagogias não tradicionais pelos professores.

Quanto aos habilitadores da Educação 4.0, os resultados sugerem que eles podem auxiliar no entendimento das necessidades educacionais exigidas pela Quarta Revolução Industrial, orientando novos modelos educacionais, fomentando às competências digitais dos professores e às soft e hard skills essenciais para o aprendizado dos estudantes. Vale ressaltar que esta proposta pode ser útil para ajudar os professores na concepção de seus planos de curso para proporcionar processos de ensino e aprendizagem para o desenvolvimento das competências da cidadania digital, além de fomentar habilidades do século XXI dos estudantes.

Este estudo possui algumas limitações, entre as quais: aplicação apenas na modalidade remota devido às medidas de prevenção contra o COVID-19, carecendo então de aplicação na modalidade presencial; avaliação por uma quantidade reduzida de professores, necessitando de aplicação e avaliação por uma maior quantidade de educadores; e uso de poucas combinações de habilitadores para Transformação Digital na Educação 4.0, podendo o uso ser estendido para outras combinações de habilitadores em contextos e realidades educacionais diferentes.

Entre as perspectivas para a continuidade da pesquisa destacam-se o desenvolvimento de um guia prático para dar suporte aos estudantes a serem equipados com às competências digitais necessárias para o 
alcance do nível de maturidade de cidadania digital, considerada a base para as novas relações sociais, profissionais e educacionais. Este guia, objetiva auxiliar os educadores no planejamento de atividades e tomada de decisão no ambiente escolar e fora dele. Além disso, a proposta pode ser executada no ambiente escolar para avaliar os resultados em relação às expectativas descritas neste trabalho.

\section{Agradecimentos}

O presente trabalho foi realizado com apoio da Coordenação de Aperfeiçoamento de Pessoal de Nível Superior - Brasil (CAPES) - Código de Financiamento 001.

\section{Referências}

Brasil. (2018). Base Nacional Comum Curricular. Recuperado a partir de http://basenacionalcomum.mec.gov.br/images/BNCC_EI_EF_110518_versaofinal_site.pdf

Buchanan, R., Southgate, E., Smith, S. P., Murray, T., \& Noble, B. (2017). Post no photos, leave no trace: Children's digital footprint management strategies. E-Learning and Digital Media, 14(5), 275-290. https://doi.org/10.1177/2042753017751711

CGI.BR. (2018). TIC KIDS ONLINE BRASIL - Pesquisa Sobre o Uso da Internet por Crianças e Adolescentes no Brasil. Recuperado a partir de https://www.cetic.br

Chen, L. L., Mirpuri, S., Rao, N., \& Law, N. (2021). Conceptualization and measurement of digital citizenship across disciplines. Educational Research Review, 100379. https://doi.org/10.1016/j.edurev.2021.100379

CIEB. Centro de Inovação para a Educação Básica. (2019). Currículo de Referência em Tecnologia e Computação. Da Educação infantil ao ensino fundamental. Recuperado a partir de https://curriculo.cieb.net.br/assets/docs/Curriculo_de_Referencia_em_Tecnologia_e_Computacao.pdf

COSI. Child Online Safety Index. (2020). Real-Time Measure for Country's Child Online Safety. Recuperado a partir de https://www.dqinstitute.org/child-online-safety-index

De Sousa Oliveira, K. K., \& Souza, R. A. C. (2020). Habilitadores da transformação digital em direção à Educação 4.0. RENOTE, 18(1). https://doi.org/10.22456/1679-1916.106012

DQ INSTITUTE. (2018). $2018 \quad \boldsymbol{D Q}$ Impact Report. Recuperado a partir de https://www.dqinstitute.org/2018DQ_Impact_Report

Fediy, O., Protsai, L., \& Gibalova, N. (2021). Pedagogical Conditions for Digital Citizenship Formation among Primary School Pupils. Revista Romaneasca pentru Educatie Multidimensionala, 13(3), 95-115. https://doi.org/10.18662/rrem/13.3/442

Joshi, D. R., Neupane, U., \& Joshi, P. R. (2021). Synthesis Review of Digital Frameworks and DEPSWALIC Digital Competency Framework for Teachers from Basic to University Level. Synthesis, 13(2), 108-136. https://commons.hostos.cuny.edu/mtrj/wp-content/uploads/sites/30/2021/07/v13n2-Synthesis-Review-ofDigital-Frameworks.pdf

OECD. Organisation for Economic Co-operation and Development. (2018). The future of education and skills: Education 2030. OECD Education 2030. OECD Publishing, Paris. Recuperado a partir de https://www.oecd.org/education/2030/E2030\%20Position\%20Paper\%20(05.04.2018).pdf

Oliveira, K. K. D. S., \& de Souza, R. A. (2021). Digital Transformation towards Education 4.0. Informatics in Education. https://doi.org/10.15388/infedu.2022.13

Oliveira, K. K. D. S., Fioravanti, M. L., Barbosa, E. F., \& Souza, R. A. C. (2021 a). Avaliação dos Habilitadores da Educação 4.0: Transformação Digital da Educação Multidisciplinar em Mudanças Climáticas. In Anais do XXXII Simpósio Brasileiro de Informática na Educação (pp. 58-67). SBC. https://doi.org/10.5753/sbie.2021.218386

Oliveira, K. K. D. S., Fioravanti, M. L., de Oliveira, M. M., Barbosa, E. F., \& Souza, R. A. C. (2021 b). Avaliando a Percepção de Inovação e Aceitação de uma Ferramenta de Suporte à Educação 4.0. In Anais do XXXII Simpósio Brasileiro de Informática na Educação (pp. 203-212). SBC. https://doi.org/10.5753/sbie.2021.218546 
Oliveira, K. K. S., Ferreira, A. S., Santana, J. R., Teixeira, V. B., \& de Souza, R. A. C. (2020). Plataforma Eco+: habilitando o comportamento ecossustentável das pessoas. GEST ÃO.Org, 18(2), 148-158. https://doi.org/10.51359/1679-1827.2020.249165.

Park, Y. (2019). DQ Global Standards Report 2019. Recuperado a partir de https://www.dqinstitute.org/wpcontent/uploads/2019/03/DQGlobalStandardsReport2019.pdf

Schleicher, A. (2016). Teaching Excellence through Professional Learning and Policy Reform: Lessons from Around the World. International Summit on the Teaching Profession, OECD Publishing, Paris. https://doi.org/10.1787/9789264252059-en

WEF. World Economic Forum. (2018). OECD, IEEE and DQI Announce Platform for Coordinating Digital Intelligence Across Technology and Education Sectors. Recuperado a partir de https://www.weforum.org/press/2018/09/oecd-ieee-and-dqi-announce-platform-forcoordinating-digitalintelligence-across-technology-and-education-sectors

WEF. World Economic Forum. Schools of the Future. (2020). Defining New Models of Education for the Fourth Industrial Revolution. In Platform for Shaping the Future of the New Economy and Society. Cologny/Geneva, $\quad$ Switzerland, 2020. Recuperado a partir de https://www3.weforum.org/docs/WEF_Schools_of_the_Future_Report_2019.pdf

Whiting, K. An expert explains: the digital risks facing our children during COVID-19. Recuperado a partir de https://www.weforum.org/agenda/2020/05/children-digital-risks-cybersecurity-screentime-covid19/ 